\title{
Crescimento e respostas fisiológicas de espécies arbóreas em solo salinizado tratado com corretivos
}

\author{
Flaubert Q. de Sousa ${ }^{1}$, Josinaldo L. Araújo ${ }^{1}$, Alexandre P. da Silva ${ }^{2}$, \\ Francisco H. F. Pereira ${ }^{1}$, Rivaldo V. dos Santos $^{3} \&$ Geovani S. de Lima ${ }^{1}$
}

\begin{abstract}
RESU M 0
O bjetivou-se com este trabalho avaliar o efeito de corretivos sobre a recuperação de um solo afetado por excesso de sais e sódio e sobre o crescimento e respostas fisiológicas de espécies arbóreas nativas da Caatinga. D ois experimentos foram realizados em casa de vegetação, ambos em delineamento inteiramente casualizado. No primeiro se avaliaram cinco tratamentos de correção do solo com quatro repetições e, no segundo experimento, os tratamentos foram arranjados em esquema fatorial $5 \times 4$, referentes a espécies arbóreas nativas da Caatinga e cinco tratamentos de correção avaliados no primeiro experimento, com três repetições. A aplicação de corretivos, especialmente de enxofre elementar, diminuiu a salinidade e a sodicidade do solo salinizado, favorecendo o crescimento e a produção de matéria seca das plantas. A espécie pau-ferro foi a que se mostrou mais tolerante ao excesso de sais e sódio. 0 excesso de sais e sódio no solo elevou os teores de sódio e a relação sódio/potássio na parte aérea das plantas, diminuiu a condutância estomática e a concentração intercelular de $\mathrm{CO}_{2}$ nos tecidos foliares.
\end{abstract}

Palavras-chave: estresse salino, correção da salinidade, espécies nativas arbóreas

\section{Growth and physiological responses of tree species in salinized soil treated with amendments}

\begin{abstract}
A B STRACT
The study aimed to evaluate the effect of amendments on the reclamation of a saline-sodic soil and on growth and physiological responses of native species of trees from Caatinga ecosystem. Two experiments were carried out in a greenhouse, in a completely randomized design. In first experiment, five treatments of soil reclamation were evaluated with four replications. In the second experiment the treatments were arranged in a factorial scheme $5 \times 4$, related to the native species of trees from Caatinga ecosystem and five treatments of reclamation evaluated in the first experiment with three replications. The application of amendments, especially elemental sulfur, decreased salinity and sodicity of salinized soil, favoring the growth and dry matter production of plants. The Caesalpinia ferrea specie was the one that was more tolerant to excess of salts and sodium. Excess of salts and sodium in the soil increased the concentration of sodium and sodium/potassium ratio in the shoots and decreased stomatal conductance and intercellular $\mathrm{CO}_{2}$ concentration in the leaves.
\end{abstract}

Key words: salt stress, salinity correction, trees native species

\footnotetext{
UAGRA/UFCG, Campus de Pombal, Rua Jairo Feitosa s/n, CEP 58840-000, Pombal, PB. Fone: (83) 3431-4000. E-mail: flaubertqueiroga@yahoo.com.br; jhosinal_araujo@yahoo.com.br; fhfpereira@hotmail.com; geovanisoareslima@gmail.com

2 U ACTA/U FCG, Campus de Pombal, Rua Jairo Feitosa s/n, CEP 58840-000, Pombal, PB. Fone: (83) 3431-4000. E-mail: paivadasilva@gmail.com 3 U AEF/U FCG, Campus de Patos, CP 64, Avenida Universitária, Jatobá - Km 1, s/n, CEP 58700-970, Patos, PB. Fone: (83) 3511-3048. E-mail: rivaldo_vital@hotmail.com
} 


\section{INTRODUÇÃO}

A salinidade do solo é um dos principais fatores responsáveis pela degradação dos solos, causando impactos negativos sobre a produção agrícola e sobre a sustentabilidade de ecossistemas, sobretudo de regiões áridas e semiáridas (Qadir et al., 2007). Mundialmente, as áreas afetadas por excesso de sais (salinidade) e/ou sódio (sodicidade) representam mais de 950 milhões de ha (Ribeiro et al., 2003). Nas áreas irrigadas os prejuízos anuais proporcionados por ambos os processos (salinização e sodificação) ultrapassam US\$ 12 bilhões (Qadir et al., 2003). No Brasil, os solos salinizados ocorrem, comumente, na região Nordeste, mais especificamente no Polígono das Secas, perfazendo $57 \%$ da área total da região semiárida, onde predomina o ecossistema conhecido por Caatinga (Gupta \& Abrol, 1990; Ribeiro et al., 2003). Nos perímetros irrigados dessa região, o processo de salinização e sodificação tem tornado os solos inadequados para o cultivo da maioria das espécies agrícolas, culminando com o abandono das terras (Ribeiro et al., 2003).

O excesso de sais no solo exerce efeitos sobre a fisiologia das plantas como resultado de interações iônicas, osmótica e nutricional e de alterações hormonais (Hazegawa et al., 2000; Taiz \& Zeiger, 2004). As principais alterações fisiológicas incluem redução na taxa de crescimento, fotossíntese, condutância estomática, transpiração e condutividade hidráulica das raízes, além de injúria e abscisão foliar (RomeroAranda, 1998; Munns, 2002). O excesso de sódio, por outro lado, eleva o $\mathrm{pH}$ do solo, causando desbalanços nutricionais e diminuindo a disponibilidade de alguns nutrientes às plantas (Taiz \& Zeiger, 2004). Além disso, em altas concentrações o sódio promove o fenômeno de dispersão de argila, proporcionando o entupimento de poros, diminuindo a capacidade de armazenamento e movimentação de água e aumentando, assim, a resistência mecânica à penetração de raízes (Ribeiro et al., 2003).

A minimização dos impactos proporcionados pelo excesso de sais em áreas irrigadas passa, necessariamente, pela adoção de técnicas de recuperação como o uso de corretivos, sendo o gesso, o ácido sulfúrico e o enxofre elementar, amplamente difundidos na literatura pertinente (Pitman \& Laüchili, 2002; Vital et al., 2005; Leite et al., 2007; Qadir et al., 2007; Stamford et al., 2007).

Dentre os corretivos o gesso (sulfato de cálcio) tem sido o mais empregado devido principalmente ao seu baixo custo em relação aos demais e aos seus efeitos positivos na melhoria dos atributos químicos e físicos do solo (Vital et al., 2005; Leite et al., 2007; Stamford et al., 2007; Zia et al., 2007; Gill et al., 2008; Leal et al., 2008; Melo et al., 2008; Pazhanivelan et al., 2008; Gharalbeh et al., 2009). O ácido sulfúrico é outro corretivo indicado para solos sódicos ou salino-sódicos e tem, como principal vantagem, sua alta eficiência em reduzir o $\mathrm{pH}$ dos solos para níveis mais apropriados ao desenvolvimento das plantas (Tertuliano \& Santos, 1998; Amezketa et al., 2005; Zia et al., 2007), proporcionando maior disponibilidade de nutrientes e maior atividade microbiana. O enxofre elementar tem sido empregado na recuperação de solos salinizados, sobremaneira naqueles afetados por excesso de sódio cujos resultados se mostraram promissores (Stamford et al., 2002; Mohamed et al., 2007; Qadir et al., 2007; Stamford et al., 2007). Seus efeitos são semelhantes aos proporcionados pelo ácido sulfúrico uma vez que, ao ser oxidado no solo por intermédio de bactérias Thiobacillus thiooxidans, ocorre a produção de ácido sulfúrico, cujo modo de ação no solo é idêntico ao do ácido sulfúrico industrializado (Stamford et al., 2002).

A utilização de espécies com maior tolerância à salinidade tem sido outra estratégia recomendada na recuperação de solos degradados pelo excesso de sais e sódio (Qadir et al., 2007). As espécies arbóreas possuem sistema radicular profundo, podendo aumentar a permeabilidade do solo, a lixiviação dos sais e controlar o nível do lençol freático (Qadir et al., 2003). Além de serem espécies de uso múltiplo, algumas têm a capacidade de fixar o nitrogênio atmosférico, contribuindo para aumentar o teor de matéria orgânica e melhorar atributos físicos e químicos do solo (Qadir et al., 2007).

De acordo com Qadir et al. (2007), os efeitos dos corretivos na recuperação de solos salinizados podem ser potencializados quando se empregam espécies mais tolerantes às condições adversas de tais solos, em especial as espécies arbóreas. Contudo, há poucos estudos avaliando o comportamento de espécies arbóreas nativas em condições de solo salino-sódico, principalmente as de ocorrência em ecossistema de Caatinga (Tertuliano \& Santos, 1998; Holanda et al., 2007).

O trabalho teve por objetivo avaliar o efeito dos corretivos sulfato de cálcio, ácido sulfúrico e enxofre elementar na correção de um solo com excesso de sais e de sódio, bem como o crescimento e respostas fisiológicas de espécies arbóreas nativas do ecossistema Caatinga.

\section{Material E MÉtodos}

Dois experimentos foram conduzidos em casa de vegetação do Centro de Ciências e Tecnologia Agroalimentar da Universidade Federal de Campina Grande (CCTA), Campus de Pombal, PB, utilizando-se amostras de um solo salino-sódico e de um solo não salino. As amostras de ambos os solos foram obtidas nas camadas de 0 - $40 \mathrm{~cm}$, em lotes pertencentes ao setor de suinocultura do Perímetro Irrigado de São Gonçalo, localizado a $10 \mathrm{~km}$ do município de Sousa, PB. Os dois solos foram classificados como Neossolo Flúvico (EMBRAPA, 2006).

Após secas ao ar, destorroadas e passadas em peneira de malha de 2,0 mm, as amostras foram encaminhadas ao Laboratório de Análises de Solos e Plantas do CCTA/UFCG para sua caracterização química e física (Tabela 1) de acordo com metodologia proposta pela EMBRAPA (1997). Foram determinados o $\mathrm{pH}$ em $\mathrm{CaCl}_{2}$ a $0,01 \mathrm{~mol} \mathrm{~L}^{-1}$, a condutividade elétrica no extrato de saturação (CEes), os teores de $\mathrm{Ca}^{+2}, \mathrm{Mg}^{+2}$, $\mathrm{H}+\mathrm{Al}^{+3}, \mathrm{Na}^{+}, \mathrm{K}^{+}$trocáveis e $\mathrm{P}$ disponível. A caracterização física constou de análise granulométrica, densidade do solo e densidade de partículas e umidade correspondente às tensões de $-0,01 ;-0,033$ e - 1,5 Mpa.

No primeiro experimento adotou-se o delineamento experimental inteiramente casualizado (DIC) com cinco tratamentos (solo salino-sódico sem corretivo; solo salinosódico + sulfato de cálcio; solo salino-sódico + ácido sulfúrico 
Tabela 1. Atributos químicos e físicos das amostras de solos antes da aplicação dos tratamentos

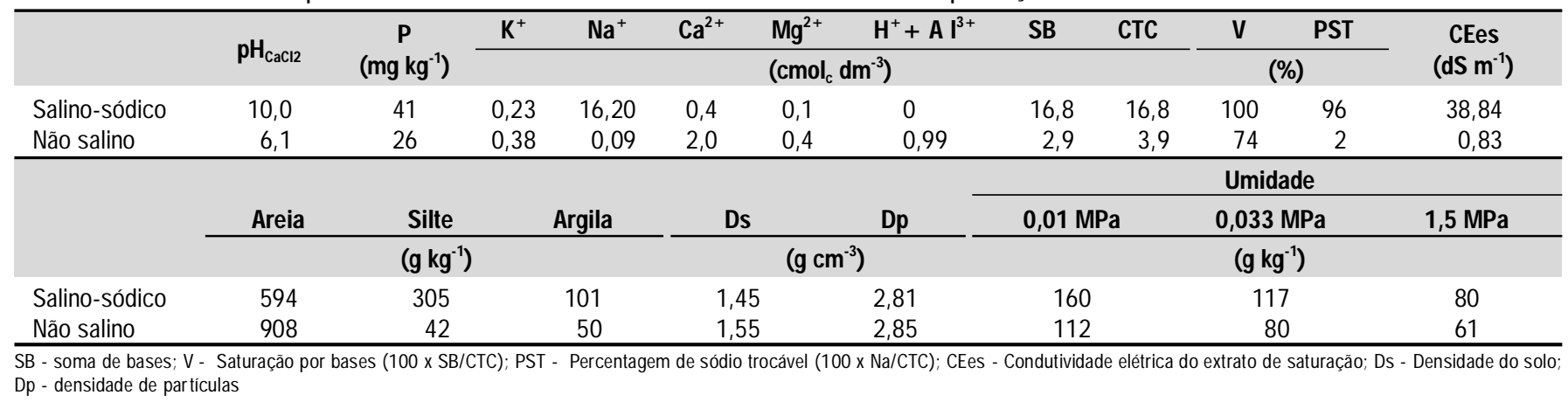

e solo salino-sódico + enxofre elementar e um solo não salino) e 12 repetições, totalizando 60 parcelas experimentais. Cada parcela foi constituída de um vaso de $5,0 \mathrm{dm}^{3}$ de solo. A dose de sulfato de cálcio p.a., foi determinada conforme Leite et al. (2007) usando a fórmula $\mathrm{NG}=0,86 \mathrm{Na}^{+}$/pureza do sulfato de cálcio, em que: $\mathrm{NG}=$ necessidade de gesso em $\mathrm{g} \mathrm{kg}^{-1}$ de solo; $\mathrm{Na}^{+} \mathrm{X}=$ teor de sódio trocável em $\mathrm{cmol}_{\mathrm{c}} \mathrm{dm}^{-3}$. As doses de ácido sulfúrico e enxofre elementar foram calculadas com base na dose de sulfato de cálcio recomendada $\left(11,76 \mathrm{~g} \mathrm{dm}^{-3}\right)$, objetivando fornecer a mesma quantidade de enxofre fornecida pelo sulfato de cálcio. Depois de diluído em água destilada o ácido foi incorporado a todo o volume de solo contido nos vasos. Após a aplicação dos corretivos os solos foram mantidos durante 20 dias com umidade correspondente a $70 \%$ da capacidade de campo.

Após este período foram aplicados: uma lâmina de lixiviação e um volume de água $\left(\mathrm{CEa}=0,15 \mathrm{dSm}^{-1}\right)$ equivalente a duas vezes a porosidade total do solo. Após a lavagem foi realizada uma amostragem em quatro das 12 repetições, para uma nova caracterização química do solo para fins de fertilidade, conforme os procedimentos descritos em EMBRAPA(1997). Nas mesmas amostras procedeu-se à caracterização da salinidade do solo avaliando-se, no extrato de saturação, a CE (condutividade elétrica), teores solúveis de $\mathrm{Na}^{+}, \mathrm{Ca}^{2+}$ e $\mathrm{Mg}^{2+}$, a PST (percentagem de sódio trocável) e a RAS (relação de adsorção de sódio) conforme procedimentos descritos em Richards (1954). Os valores da PST e da RAS foram estimados pelas Eqs. 1 e 2 conforme Richards (1954):

$$
\begin{gathered}
\mathrm{RAS}=\frac{\mathrm{Na}}{\sqrt{(\mathrm{Ca}+\mathrm{Mg}) / 2}} \\
\mathrm{PST}=\frac{100(0,01475 \mathrm{RAS}-0,0126)}{1+(0,01475 \mathrm{RAS}-0,0126)}
\end{gathered}
$$

em que:

$\mathrm{Na}, \mathrm{Ca}$ e $\mathrm{Mg}$ - teores solúveis em $\mathrm{mmol}_{\mathrm{c}} \mathrm{L}^{-1}$ desses íons

No segundo experimento, também conduzido em DIC, os tratamentos foram arranjados em esquema fatorial $5 \times 4$, referente a quatro espécies arbóreas [(Anadenanthera macrocarpa (Vell.) Brenan - angico), (Myracrodruon urundeuva -aroeira), Caesalpinia pyramidalis Tul. - catingueira), Caesalpinia ferrea
- pau-ferro)] e cinco tratamentos de correção (solo salino-sódico sem corretivo; solo salino-sódico + sulfato de cálcio; solo salino-sódico + ácido sulfúrico e solo salino-sódico + enxofre elementar e um tratamento com um solo não salino) obtidos no primeiro experimento, com três repetições, totalizando 60 parcelas experimentais. As parcelas experimentais foram constituídas de um vaso com duas plantas.

As sementes das espécies foram germinadas em tubetes de $300 \mathrm{~mL}$ preenchidos com substrato à base solo de barranco, areia e esterco bovino, na proporção de um terço de cada componente. Após cerca de $15 \mathrm{~cm}$ de altura, as plântulas foram selecionadas pela uniformidade e transferidas para os vasos com os solos já "lavados", com os respectivos tratamentos; ocasião em que foram tomados os valores de altura de cada planta no tempo zero, para fins de cálculo do incremento em altura das plantas. Antes do transplantio e após a lavagem do solo em todos os vasos, foi realizada uma adubação básica com nitrogênio, fósforo, potássio, magnésio e micronutrientes, conforme Malavolta (1980). Os macronutrientes foram fornecidos na forma sólida utilizando-se reagentes p.a., homogeneizando-os a todo o volume de solo. A adubação foliar com micronutrientes consistiu na pulverização foliar das plântulas com uma solução de micronutrientes contendo cobre, manganês, ferro e zinco, na forma de sulfato de cobre $\left(\mathrm{CuSO}_{4}\right.$ $\left.5 \mathrm{H}_{2} \mathrm{O}\right)$, cloreto de manganês $\left(\mathrm{MnCl}_{2} 4 \mathrm{H}_{2} \mathrm{O}\right)$, sulfato ferroso $\left(\mathrm{FeSO}_{4} 7 \mathrm{H}_{2} \mathrm{O}\right)$ e sulfato de zinco $\left(\mathrm{ZnSO}_{4} 7 \mathrm{H}_{2} \mathrm{O}\right)$, usando-se fontes p.a. $\mathrm{O}$ fornecimento de micronurientes foi realizado em duas etapas, ou seja, a primeira logo após o transplantio e a segunda trinta dias depois.

Durante os 75 dias após transplantio foram realizadas medições quinzenais da altura das plantas, período após o qual foram avaliadas, também nas mesmas, por meio de método não destrutivo, as taxas de transpiração, fotossíntese líquida e condutância estomática utilizando-se o analisador de gás infravermelho - IRGA(Infra-red Gas Analyzer). Posteriormente, as partes aéreas das plantas foram separadas das raízes, que foram secas em estufa a $65-70{ }^{\circ} \mathrm{C}$ para obtenção da matéria seca da parte aérea (MSPA) e de raízes (MSR). Na MSPA e na MSR foram determinados os teores de sódio e potássio conforme procedimentos descritos em Malavolta et al. (1997). De posse dos valores de crescimento em altura de planta, MSPA e MSR, foram estimados os valores de crescimento relativo em altura e a produção relativa de MSPA e MSR das espécies.

Em ambos os experimentos a análise estatística constou de análise de variância, teste de médias (Tukey), utilizando-se o 
software SISVAR 4.0 e a análise de correlação linear simples dessas variáveis, através do software SAEG 9.0 adotando-se, em todas as análises, nível de 5\% de probabilidade.

\section{RESULTADOS E DISCUSSÃO}

\section{Efeito dos corretivos na recuperação do solo}

Os tratamentos de correção afetaram todos os atributos químicos dos solos. A aplicação dos corretivos proporcionou no solo salino-sódico, decréscimos nos valores de $\mathrm{pH}$, da $\mathrm{CE}_{1: 5}$ (condutividade elétrica do obtido na proporção solo:água 1:5), nos teores de $\mathrm{Na}^{+}$trocável e na PST (Tabela 2). Contudo, os valores dessas variáveis obtidas no solo salino-sódico com ou sem corretivo, foram sempre superiores aos do solo não salino. Por outro lado, a aplicação dos corretivos ao solo salino-

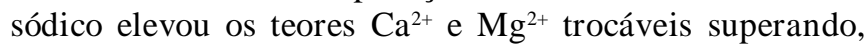
inclusive, os teores obtidos no solo não salino. Os teores trocáveis de $\mathrm{K}^{+}$não foram alterados pela aplicação dos corretivos ao solo salino-sódico, embora tenham sido superiores para o solo não salino (Tabela 2). Entre os corretivos o sulfato de cálcio foi o que mais reduziu a PST, enquanto o ácido sulfúrico e o enxofre elementar, ambos de reação ácida, foram os que mais reduziram os valores de $\mathrm{pH}$ do solo. Observou-se ainda que o sulfato de cálcio, embora de reação neutra, também diminuiu o pH do solo salino-sódico (Tabela 2).

A diminuição dos valores de $\mathrm{pH}, \mathrm{CE}_{1: 5}$ e os teores trocáveis de $\mathrm{Na}$ pela aplicação do sulfato de cálcio são decorrentes principalmente do deslocamento do sódio do complexo de troca pelo cálcio liberado pelo corretivo (Vital et al., 2005). Neste processo o sódio é deslocado para a solução do solo visando reagir com os ânions sulfatos, formando sulfato de sódio o qual é removido após a aplicação de uma lâmina de água. Assim, o sulfato de cálcio favoreceu a lixiviação de sódio e íons $\mathrm{HCO}_{3}^{-}$, contribuindo, desta forma, para a diminuição do $\mathrm{pH}$ do solo (Vital et al., 2005; Leite et al., 2007).

Quanto ao enxofre, seu efeito no abaixamento do $\mathrm{pH}$ do solo salino-sódico se deve, provavelmente, à sua oxidação biológica, a qual gera ácido sulfúrico no solo (Stamford et al., 2002). A diminuição do pH do solo pela aplicação de ácido sulfúrico era prevista; entretanto, também se observou um

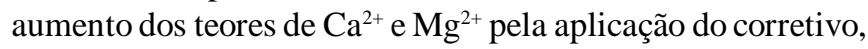
tal como ocorreu com a aplicação do enxofre elementar. Tal fato é devido, provavelmente, à ação dos íons $\mathrm{H}^{+}$gerados por ambos os corretivos, na solubilização de minerais primários do solo contendo os referido cátions (Amezketa et al., 2005). Tanto o enxofre quanto o ácido sulfúrico liberam íons sulfatos no solo, os quais reagem com o sódio na solução do solo, para removêlo do complexo de troca, o que também contribui para o abaixamento do $\mathrm{pH}$ do solo.

Os atributos químicos obtidos do extrato de saturação do solo (Tabela 3) apresentaram comportamento semelhante aos do complexo sortivo (Tabela 2). Verificou-se redução dos valores de CEes, dos teores solúveis de $\mathrm{Na}^{+}$, PST e RAS no solo salino-sódico com a aplicação dos corretivos (Tabela 3), embora quando comparado com o solo não salino seus valores tenham permanecido ainda muito superiores. Por outro lado, a aplicação de sulfato de cálcio ou ácido sulfúrico ao solo salinosódico promoveu acréscimos nos teores de $\mathrm{Ca}^{2+}+\mathrm{Mg}^{2+}$ solúveis em relação aos demais tratamentos, como ocorrido com os teores trocáveis desses cátions (Tabela 3). Dentre os corretivos se destacaram, na redução da salinidade (CEes) e da sodicidade ( $\mathrm{Na}^{+}$, PST e RAS) do extrato de saturação, o enxofre elementar e o ácido sulfúrico.

A aplicação dos corretivos ao solo salino-sódico melhorou consideravelmente os atributos químicos do solo. Contudo, os valores obtidos para as variáveis que expressam a salinidade e a sodicidade do solo ainda permaneceram elevados em relação ao solo não salino e aos valores de referência capazes de

Tabela 2. Atributos químicos dos solos após a aplicação dos tratamentos e da lâmina de lixiviação

\begin{tabular}{|c|c|c|c|c|c|c|}
\hline \multirow{2}{*}{ Correção do solo } & \multirow{2}{*}{$\mathrm{pH}_{\mathrm{CaCl} 12}$} & \multirow{2}{*}{$\begin{array}{c}\mathrm{CE}_{1: 5} \\
\left(\mathrm{dSS}^{-1}\right)\end{array}$} & $\mathbf{K}^{+}$ & $\mathrm{Na}^{+}$ & $\mathrm{Ca}^{2+}$ & $\mathrm{Mg}^{2+}$ \\
\hline & & & \multicolumn{4}{|c|}{$\left(\mathrm{cmol}_{\mathrm{c}} \mathrm{dm}^{-3}\right)$} \\
\hline Salino-sódico sem corretivo & $10,2 a^{*}$ & $1,78 \mathrm{a}$ & $0,15 b$ & $12,57 \mathrm{a}$ & $0,40 d$ & $0,30 d$ \\
\hline Salino-sódico $+\mathrm{CaSO}_{4} 2 \mathrm{H}_{2} \mathrm{O}$ & $8,7 \mathrm{~b}$ & $0,72 b$ & $0,15 b$ & $5,57 \mathrm{~b}$ & $7,12 \mathrm{a}$ & $0,95 \mathrm{c}$ \\
\hline Salino-sódico + enxofre & $8,2 c$ & $0,61 b$ & $0,16 \mathrm{~b}$ & $5,90 \mathrm{~b}$ & $4,11 b$ & $1,56 \mathrm{~b}$ \\
\hline Salino-sódico $+\mathrm{H}_{2} \mathrm{SO}_{4}$ & $7,9 c$ & $0,96 \mathrm{~b}$ & $0,17 \mathrm{~b}$ & $6,70 \mathrm{~b}$ & $6,15 a$ & $2,80 \mathrm{a}$ \\
\hline Não salino & $6,7 d$ & $0,08 \mathrm{c}$ & $0,24 a$ & $0,15 \mathrm{c}$ & $2,83 \mathrm{c}$ & $1,04 \mathrm{bc}$ \\
\hline CV (\%) & 2,3 & 21,6 & 7,1 & 11,9 & 11,4 & 19,6 \\
\hline
\end{tabular}

* Médias seguidas de letras iguais, nas colunas, não diferem entre si (Tukey a 5\%). $\mathrm{CE}_{1: 5}{ }^{-}$condutividade elétrica obtida no extrato da relação solo:água 1:5

Tabela 3. Atributos químicos do extrato de saturação dos solos após a aplicação dos tratamentos e da lâmina de lixiviação

\begin{tabular}{|c|c|c|c|c|c|}
\hline \multirow{2}{*}{ Correção do solo } & \multirow{2}{*}{$\begin{array}{c}\mathrm{CE}_{\mathrm{es}} \\
\left(\mathrm{d} S \mathrm{~m}^{-1}\right)\end{array}$} & $\mathrm{Na}^{+}$ & $\mathrm{Ca}^{2+}+\mathrm{Mg}^{2+}$ & \multirow{2}{*}{$\begin{array}{l}\text { PST } \\
(\%)\end{array}$} & \multirow{2}{*}{$\begin{array}{c}\text { RAS } \\
\left(\mathrm{mmol}_{\mathrm{c}} \mathrm{L}^{-1}\right)^{0,5}\end{array}$} \\
\hline & & \multicolumn{2}{|c|}{$\left(\mathrm{mmol}_{\mathrm{c}} \mathrm{L}^{-1}\right)$} & & \\
\hline Salino-sódico sem corretivo & $26,47 a^{*}$ & $241,01 \mathrm{a}$ & $2,00 \mathrm{C}$ & 69,62 a & $277,34 \mathrm{a}$ \\
\hline Salino-sódico $+\mathrm{CaSO}_{4} 2 \mathrm{H}_{2} \mathrm{O}$ & $14,14 \mathrm{~b}$ & $136,08 \mathrm{~b}$ & $7,31 b$ & $54,98 a b$ & $73,32 b$ \\
\hline Salino-sódico + enxofre & $15,90 \mathrm{~b}$ & $84,52 \mathrm{c}$ & $13,94 \mathrm{a}$ & $34,16 \mathrm{c}$ & $36,04 \mathrm{c}$ \\
\hline Salino-sódico $+\mathrm{H}_{2} \mathrm{SO}_{4}$ & $9,41 \mathrm{C}$ & $132,86 \mathrm{~b}$ & $16,50 \mathrm{a}$ & $40,60 \mathrm{bc}$ & $47,55 c$ \\
\hline Não salino & $1,11 \mathrm{~d}$ & $1,56 \mathrm{~d}$ & $2,67 \mathrm{c}$ & $0,78 d$ & $1,39 d$ \\
\hline CV (\%) & 17,0 & 10,3 & 24,6 & 19,2 & 12,5 \\
\hline
\end{tabular}

* Médias seguidas de letras iguais, nas colunas, não diferem entre si (Tukey a 5\%). CEes - Condutividade elétrica do extrato de saturação; PST - percentagem de sódio trocável; RAS - relação de adsorção de sódio 
proporcionar decréscimos no crescimento e na produtividade da maioria das culturas (Richards, 1954). Contudo, devido à variação na tolerância à salinidade e sodicidade entre as espécies vegetais torna-se possível selecionar espécies mais adequadas para determinado nível de salinidade e/ou sodicidade (Qadir et al., 2007).

\section{Efeito dos corretivos sobre o crescimento e produção de maté- ria seca das plantas}

A evolução do crescimento em altura das plantas variou conforme a espécie vegetal e os tratamentos de correção do solo. Em relação às espécies, o pau-ferro foi a que atingiu os maiores valores de altura após 75 dias do transplantio (Figura 1). Em todas as épocas as plantas apresentaram maior crescimento quando cultivadas no solo não salino; porém, quando cultivadas em solo salino-sódico, sem corretivo, as plantas tiveram seu crescimento praticamente paralisado. Entre os tratamentos envolvendo corretivos a partir dos 30 dias após o transplantio (DAT), verificou-se que, para o angico e a catingueira, o enxofre elementar foi o corretivo que proporcionou o maior crescimento em altura, enquanto para as demais espécies os valores obtidos com o enxofre elementar e o sulfato de cálcio superaram os do corretivo ácido sulfúrico, embora semelhantes entre si (Figura 1).

O crescimento relativo em altura (CRA), a produção relativa de matéria seca da parte aérea (MSRPA) e de raízes (MSRR) das plantas após 75 dias do transplantio, que expressam a percentagem do crescimento das plantas no solo salino-sódico em relação ao solo não salino, foram influenciados pela espécie vegetal, pelos tratamentos de correção do solo e pela interação entre esses fatores. Em geral, os maiores valores dessas variáveis foram obtidos com o uso do corretivo enxofre elementar, embora sem haver diferença entre este e o sulfato de cálcio (Figura 2).

Comparando-se as espécies vegetais, o pau-ferro apresentou os maiores valores de CRA, MSRPA e MSRR em todos os tratamentos de correção do solo (Figura 2). Com a aplicação de ácido sulfúrico, sulfato de cálcio ou enxofre elementar, a espécie pau-ferro apresentou valores de MSRPA (Figura 2B) superiores 70\% indicando, conforme critérios de Fageria (1985) tratar-se de uma espécie moderadamente tolerante à salinidade do solo apresentada nesses tratamentos. Pelo mesmo critério, as demais espécies, com exceção do angico no tratamento com enxofre elementar, seriam consideradas sensíveis à salinidade. Em condições de solo salinizado não foram encontradas referências sobre a tolerância das espécies avaliadas no presente trabalho embora Freitas et al. (2010) tenham observado, recentemente, que na fase de germinação da espécie pau-ferro a maioria das características associadas ao processo germinativo, com solução salina de 4,5 $\mathrm{dSm}^{-1}$ apresentou valores acima de $50 \%$ em relação às sementes germinadas com solução não salina, demonstrando tolerância moderada à salinidade pela espécie nesta fase.

Como observado, o crescimento e a produção de matéria seca das plantas no solo degradado sem corretivos foram consideravelmente diminuídos. A redução do crescimento ocorre sobremaneira devido à toxidez de íons específicos como o sódio e ao baixo potencial osmótico da solução do solo,
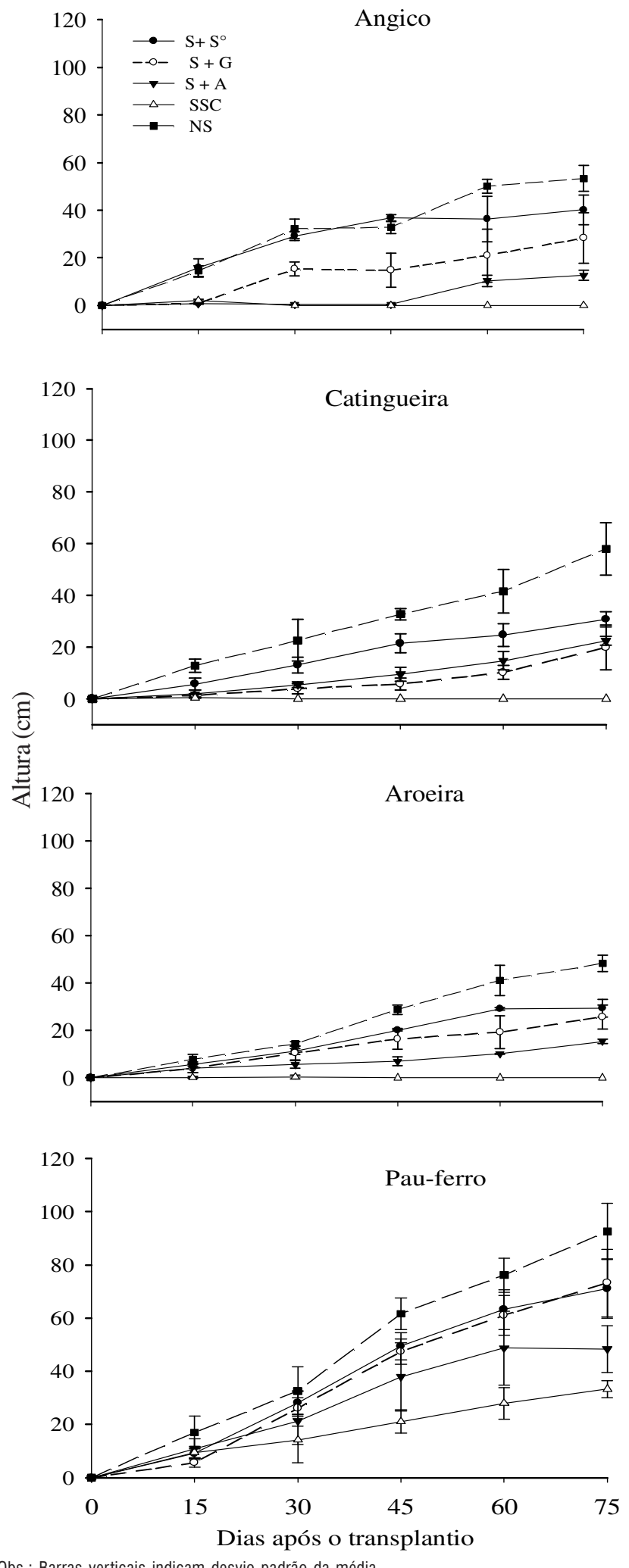

Obs.: Barras verticais indicam desvio padrão da média

Figura 1. Incremento em altura das espécies vegetais em função dos tratamentos: solo salino-sódico corrigido com enxofre $\left(\mathrm{S}+\mathrm{S}^{\circ}\right)$, corrigido com sulfato de cálcio ( $\mathrm{S}$ $+\mathrm{G})$, corrigido com ácido sulfúrico $(\mathrm{S}+\mathrm{A})$, sem corretivo (SSC) e solo não salino (NS)

causando estresse hídrico (Munns, 2002; Taiz \& Zeiger, 2004). A aplicação de enxofre elementar ou sulfato de cálcio ao solo, 


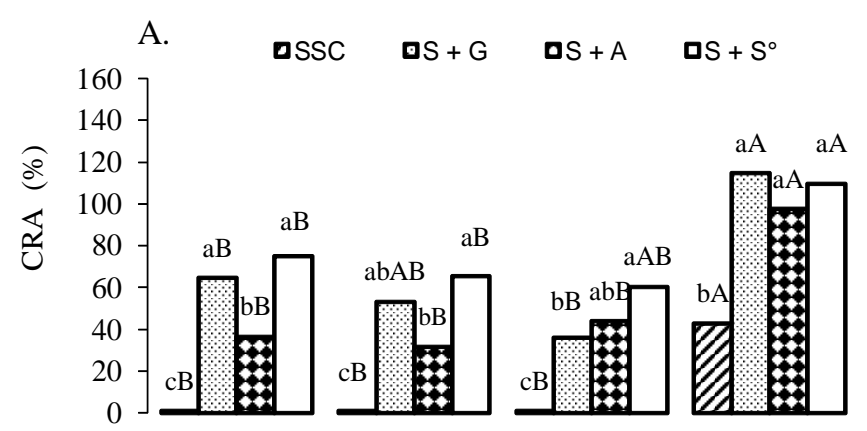

B.

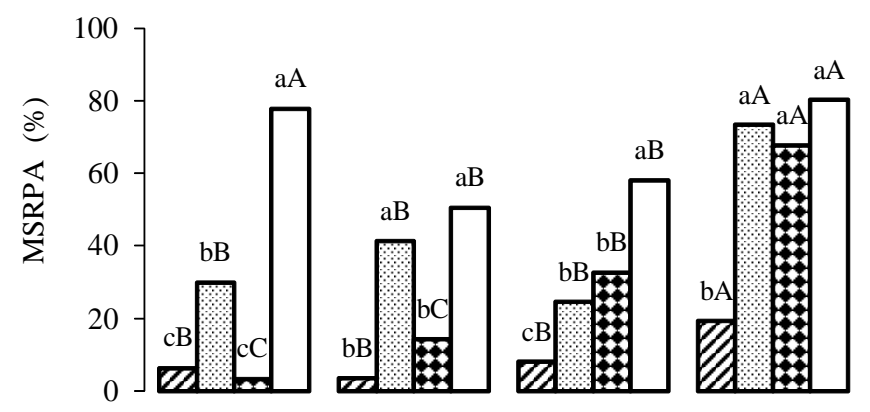

C.

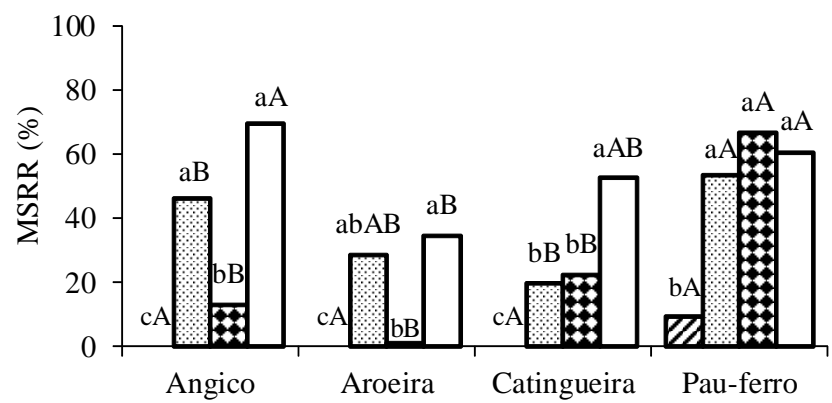

* Médias seguidas de letras iguais, minúsculas comparando os tratamentos de correção do solo e maiúsculas comparando as espécies vegetais, não diferem entre si pelo teste de Tukey a $5 \%$

Figura 2. Crescimento relativo em altura (CRA)(A) e produção relativa de matéria seca da parte aérea (MSRPA) (B) e de raízes (M SRR) (C) em função dos tratamentos: solo salino-sódico sem corretivo (SSC), corrigido com ácido sulfúrico $(S+A)$, corrigido com sulfato de cál cio $(S+G)$ ou corrigido com enxofre elementar $\left(S+S^{\circ}\right)$ das espécies vegetais

entretanto, favoreceu o crescimento e a produção de matéria seca das espécies vegetais avaliadas fato devido, possivelmente, ao estabelecimento de melhores condições químicas no solo por esses corretivos, principalmente pela diminuição dos teores de sódio trocável, da condutividade elétrica e da PST (Tabelas 2 e 3 ).

Teores de sódio e potássio na parte aérea e respostas fisiológicas

Os teores de sódio e de potássio e a relação sódio/potássio, tal como a taxa de transpiração, concentração intercelular de $\mathrm{CO}_{2}$, fotossíntese líquida e condutância estomática, foram influenciados pelas espécies vegetais, pelos tratamentos de correção do solo e pela interação entre esses fatores. Os teores de sódio na parte aérea das plantas foram inferiores quando as plantas foram cultivadas no solo não salino, refletindo os baixos teores deste elemento neste solo (Tabela 4). Comparando-se os tratamentos relativos à correção do solo salino-sódico, a resposta foi dependente da espécie vegetal, tendo a aroeira apresentado o mais baixo teor de sódio na parte aérea com a aplicação de enxofre elementar no solo. Para as demais espécies vegetais não foi observada diferença entre os tratamentos envolvendo a aplicação dos corretivos sulfato de cálcio, enxofre elementar e ácido sulfúrico. Entre as espécies vegetais observou-se que, em geral, o pau-ferro apresentou os menores teores de sódio na parte aérea, principalmente com ácido sulfúrico ou sulfato de cálcio (Tabela 4).

Tabela 4. Teores de sódio ( $\mathrm{N}$ a) e potássio $(\mathrm{K})$ e relação $\mathrm{N}$ a/K na matéria seca da parte aérea das espécies vegetais em função dos tratamentos de correção do solo

\begin{tabular}{|c|c|c|c|c|}
\hline \multirow{2}{*}{ Correção do solo } & \multicolumn{4}{|c|}{ Espécie vegetal } \\
\hline & Angico & Aroeira & Catingueira & Pau-ferro \\
\hline & \multicolumn{4}{|c|}{$\mathrm{Na}\left(\mathrm{g} \mathrm{kg}^{-1}\right)$} \\
\hline Salino-sódico sem corretivo & nd & nd & nd & nd \\
\hline Salino-sódico $+\mathrm{CaSO}_{4} 2 \mathrm{H}_{2} \mathrm{O}$ & $2,75 \mathrm{aB}^{*}$ & $12,04 \mathrm{aA}$ & $5,16 \mathrm{aB}$ & $2,25 \mathrm{abC}$ \\
\hline Salino-sódico $+\mathrm{H}_{2} \mathrm{SO}_{4}$ & $2,26 \mathrm{aB}$ & $6,61 \mathrm{bA}$ & $5,64 \mathrm{aA}$ & $1,57 \mathrm{abB}$ \\
\hline Salino-sódico + enxofre & $2,02 \mathrm{aB}$ & $2,99 \mathrm{cB}$ & $6,13 \mathrm{aA}$ & $3,23 \mathrm{aB}$ \\
\hline \multirow[t]{2}{*}{ Solo não salino } & $1,53 \mathrm{bA}$ & $1,31 \mathrm{dA}$ & $2,02 \mathrm{bA}$ & $0,92 \mathrm{bA}$ \\
\hline & \multicolumn{4}{|c|}{$\mathrm{K}\left(\mathrm{g} \mathrm{kg}^{-1}\right)$} \\
\hline Salino-sódico sem corretivo & nd & nd & nd & nd \\
\hline Salino-sódico $+\mathrm{CaSO}_{4} 2 \mathrm{H}_{2} \mathrm{O}$ & $8,67 \mathrm{aB}$ & $21,24 \mathrm{bA}$ & $9,47 \mathrm{bB}$ & $12,56 \mathrm{abB}$ \\
\hline Salino-sódico $+\mathrm{H}_{2} \mathrm{SO}_{4}$ & $8,53 \mathrm{aB}$ & $18,54 \mathrm{bA}$ & $8,44 \mathrm{bB}$ & $9,66 \mathrm{bB}$ \\
\hline Salino-sódico + enxofre & $10,40 \mathrm{aBC}$ & $19,77 \mathrm{bA}$ & $9,96 b C$ & $14,71 \mathrm{aB}$ \\
\hline \multirow[t]{2}{*}{ Solo não salino } & $10,89 \mathrm{aC}$ & $25,65 a A$ & $17,80 \mathrm{aB}$ & $11,53 a b c$ \\
\hline & \multicolumn{4}{|c|}{$\mathrm{Na} / \mathrm{K}$} \\
\hline Salino-sódico sem corretivo & nd & nd & nd & nd \\
\hline Salino-sódico $+\mathrm{CaSO}_{4} 2 \mathrm{H}_{2} \mathrm{O}$ & $3,22 \mathrm{bAB}$ & $5,67 \mathrm{aA}$ & $5,51 \mathrm{aA}$ & $1,79 \mathrm{aB}$ \\
\hline Salino-sódico $+\mathrm{H}_{2} \mathrm{SO}_{4}$ & $2,65 a B$ & $3,54 a b B$ & $6,76 \mathrm{aA}$ & $1,63 \mathrm{aB}$ \\
\hline Salino-sódico + enxofre & $1,97 \mathrm{aB}$ & $1,61 \mathrm{aB}$ & $6,41 \mathrm{aA}$ & $2,17 \mathrm{aB}$ \\
\hline Solo não salino & $1,42 \mathrm{aB}$ & $0,52 \mathrm{cA}$ & $1,14 \mathrm{bA}$ & $0,08 \mathrm{bA}$ \\
\hline
\end{tabular}

* Médias seguidas de letras iguais minúsculas, comparando-se os tratamentos de correção do solo e maiúsculas comparando-se as espécies vegetais, não diferem entre si (Tukey a $5 \%$ ). nd - não determinado devido a produção de matéria seca insuficiente para análise

Em relação ao potássio os maiores teores foram observados para as espécies aroeira e catingueira no solo não salino enquanto nas outras espécies foi constatada pequena variação entre os tratamentos de correção do solo. Comparando-se as espécies, a aroeira obteve os maiores teores de potássio na parte aérea, em todos os tratamentos de correção do solo. As mais baixas relações sódio/potássio foram observadas no tratamento com solo não salino, independentemente da espécie vegetal. Entre as espécies vegetais o pau-ferro exibiu, em geral, as menores relações sódio/potássio, em especial nos tratamentos com sulfato de cálcio ou ácido sulfúrico.

Com relação às respostas fisiológicas das plantas observouse que, em geral, o enxofre aplicado ao solo salino-sódico proporcionou, nas espécies aroeira e pau-ferro, valores para a concentração intercelular de $\mathrm{CO}_{2}$, condutância estomática e taxa fotossintética, em geral semelhantes ou superiores aos solo não salino (Tabela 5). Ainda para a espécie aroeira verificou-se que as maiores taxas de transpiração foram observadas no solo não salino e no solo salino-sódico tratados 
com enxofre elementar. Contudo, para as demais espécies esta variável não foi influenciada pelos tratamentos de correção do solo e as respostas fisiológicas para as demais espécies aos tratamentos de correção do solo salino-sódico não apresentaram padrão definido.

Tabela 5. Respostas fisiológicas das espécies vegetais arbóreas em função dos tratamentos de correção do solo

\begin{tabular}{|c|c|c|c|c|}
\hline \multirow{2}{*}{ Correção do solo } & \multicolumn{4}{|c|}{ Espécie vegetal } \\
\hline & Angico & Aroeira & Catingueira & Pau-ferro \\
\hline $\begin{array}{l}\text { Salino-sódico sem corretivo } \\
\text { Salino-sódico }+\mathrm{CaSO}_{4} 2 \mathrm{H}_{2} \mathrm{O} \\
\text { Salino-sódico }+ \text { enxofre } \\
\text { Salino-sódico }+\mathrm{H}_{2} \mathrm{SO}_{4} \\
\text { Não salino }\end{array}$ & $\begin{array}{l}\text { Concent } \\
\quad n d \\
240,2 \mathrm{aAB} \\
261,5 \mathrm{aB} \\
237,7 \mathrm{aBC} \\
239,0 \mathrm{aB}\end{array}$ & $\begin{array}{l}\text { ração interce } \\
\text { nd } \\
211,7 \mathrm{cB} \\
309,5 \mathrm{aA} \\
273,7 \mathrm{bA} \\
245,2 \mathrm{bcAB}\end{array}$ & $\begin{array}{c}\text { elular de } \mathrm{CO}_{2} \\
\text { nd } \\
249,0 \text { aA } \\
244,5 \mathrm{aB} \\
257,0 \mathrm{aAB} \\
275,7 \mathrm{aA}\end{array}$ & $\begin{array}{c}2\left(\mathrm{mg} \mathrm{L}^{-1}\right) \\
n d \\
221,0 \mathrm{bAB} \\
256,7 \mathrm{aB} \\
221,2 \mathrm{bC} \\
258,0 \mathrm{aAB}\end{array}$ \\
\hline $\begin{array}{l}\text { Salino-sódico sem corretivo } \\
\text { Salino-sódico }+\mathrm{CaSO}_{4} 2 \mathrm{H}_{2} \mathrm{O} \\
\text { Salino-sódico }+ \text { enxofre } \\
\text { Salino-sódico }+\mathrm{H}_{2} \mathrm{SO}_{4} \\
\text { Não salino }\end{array}$ & $\begin{array}{l}\quad \mathrm{nd} \\
2,93 \mathrm{aA}^{*} \\
2,67 \mathrm{aA} \\
3,08 \mathrm{aAB} \\
2,61 \mathrm{aA} \\
\end{array}$ & $\begin{array}{c}\text { anspiração } \\
\text { nd } \\
1,95 \mathrm{bcB} \\
1,61 \mathrm{cB} \\
2,67 \mathrm{aB} \\
2,58 \mathrm{abA} \\
\end{array}$ & $\begin{array}{c}\mathrm{mmol} \mathrm{m}^{-2} \mathrm{~s} \\
\text { nd } \\
2,94 \mathrm{aA} \\
2,79 \mathrm{aA} \\
3,47 \mathrm{aA} \\
3,12 \mathrm{aA} \\
\end{array}$ & $\begin{array}{c}\text { nd } \\
2,70 \mathrm{aA} \\
2,60 \mathrm{aA} \\
2,68 \mathrm{aB} \\
2,59 \mathrm{aA} \\
\end{array}$ \\
\hline $\begin{array}{l}\text { Salino-sódico sem corretivo } \\
\text { Salino-sódico }+\mathrm{CaSO}_{4} 2 \mathrm{H}_{2} \mathrm{O} \\
\text { Salino-sódico }+ \text { enxofre } \\
\text { Salino-sódico }+\mathrm{H}_{2} \mathrm{SO}_{4} \\
\text { Não salino }\end{array}$ & $\begin{array}{l}\text { Cond } \\
\text { nd } \\
0,20 \mathrm{abA} \\
0,22 \mathrm{aA} \\
0,22 \mathrm{aA} \\
0,14 \mathrm{bB}\end{array}$ & $\begin{array}{c}\text { tância eston } \\
\text { nd } \\
0,10 \mathrm{bB} \\
0,10 \mathrm{bB} \\
0,13 \mathrm{abB} \\
0,18 \mathrm{aB}\end{array}$ & $\begin{array}{c}\text { mática (mol } n \\
\text { nd } \\
0,20 \mathrm{cA} \\
0,23 \mathrm{bcA} \\
0,28 \mathrm{abA} \\
0,31 \mathrm{aA}\end{array}$ & $\begin{array}{c}\left.\mathrm{m}^{-2} \mathrm{~s}^{-1}\right) \\
\text { nd } \\
0,15 \mathrm{bAB} \\
0,26 \mathrm{aA} \\
0,14 \mathrm{bB} \\
0,20 \mathrm{bB}\end{array}$ \\
\hline $\begin{array}{l}\text { Salino-sódico sem corretivo } \\
\text { Salino-sódico }+\mathrm{CaSO}_{4} 2 \mathrm{H}_{2} \mathrm{O} \\
\text { Salino-sódico }+ \text { enxofre } \\
\text { Salino-sódico }+\mathrm{H}_{2} \mathrm{SO}_{4} \\
\text { Não salino }\end{array}$ & $\begin{array}{l}\text { Foto } \\
\text { nd } \\
10,39 \mathrm{aA} \\
10,83 \mathrm{aA} \\
11,74 \mathrm{aA} \\
8,23 \mathrm{bB}\end{array}$ & $\begin{array}{c}\text { ssíntese líqui } \\
\text { nd } \\
7,70 \mathrm{bB} \\
3,25 \mathrm{cB} \\
5,07 \mathrm{cC} \\
10,42 \mathrm{aA}\end{array}$ & $\begin{array}{c}\text { dida }(\mu \mathrm{mol} \mathrm{m} \\
\text { nd } \\
10,04 \mathrm{bA} \\
12,11 \mathrm{aA} \\
11,48 \mathrm{abA} \\
10,73 \mathrm{abA}\end{array}$ & $\begin{array}{c}\left.\mathrm{d}^{-2} \mathrm{~s}^{-1}\right) \\
\text { nd } \\
9,76 \mathrm{bA} \\
12,24 \mathrm{aA} \\
9,13 \mathrm{bB} \\
9,72 \mathrm{bAB}\end{array}$ \\
\hline
\end{tabular}

* Médias seguidas de letras iguais, minúsculas comparando-se os tratamentos de correção do solo e maiúsculas comparando-se as espécies vegetais, não diferem entre si (Tukey a $5 \%$ ). nd - não determinado por falta de material vegetal fresco

Comparando-se as espécies vegetais observou-se que a espécie aroeira exibiu menores valores de taxa de transpiração, condutância estomática e taxa fotossintética (Tabela 5) a qual, juntamente com a espécie angico, apresentou um dos menores valores de produção relativa de matéria seca (Figura 2). Para as demais espécies as diferenças foram dependentes do tratamento de correção do solo.

Como se observa nas Tabelas 2 e 3, os tratamentos de correção do solo resultaram em níveis de salinidade e de sodicidade no solo variáveis após sua lavagem. Assim, esperarse-ia que as respostas fisiológicas das plantas seguissem um padrão definido, ou seja, que seus valores decrescessem nos tratamentos com maior nível de salinidade. Entretanto, este comportamento não pôde ser observado em razão da impossibilidade da avaliação das plantas cultivadas no solo salino-sódico sem corretivo, uma vez que as mesmas não resistiram ao excesso de sais e sódio no solo. Assim, os efeitos dos tratamentos sobre as variáveis avaliadas, incluindo-se as respostas fisiológicas, podem ser mais bem visualizados por meio de correlações simples entre variáveis (Tabela 6).

Observando o estudo de correlação (Tabela 6), conclui-se que a diminuição do crescimento e da produção de matéria
Tabela 6. Coeficientes de correlação de Pearson entre as variáveis percentagem de sódio trocável (PST), condutividade elétrica do extrato de saturação (CEes), teores solúveis de sódio no solo ( $\mathrm{Na-solo),} \mathrm{teores} \mathrm{de} \mathrm{sódio}$ na parte aérea ( $\mathrm{Na}$ a-Pa), matéria seca total (M ST), relação sódio/potássio ( $\mathrm{Na/K}$ ) na parte aérea, concentração interna de $\mathrm{CO}_{2}(\mathrm{Ci})$, condutância estomática (Cond) e taxa fotossintética (Fotos)

\begin{tabular}{|c|c|c|c|c|c|c|}
\hline & $\mathrm{Na} / \mathrm{K}$ & $\mathrm{Na}-\mathrm{Pa}$ & MST & $\mathrm{Ci}$ & Cond & Fotos \\
\hline $\begin{array}{l}\mathrm{PST} \\
\mathrm{CE}_{\text {es }} \\
\mathrm{Na}-\mathrm{Solo} \\
\mathrm{Na} / \mathrm{K} \\
\mathrm{Na}-\mathrm{Pa} \\
\mathrm{MST}\end{array}$ & $\begin{array}{c}0,86^{*} \\
0,89^{*} \\
0,92^{*} \\
- \\
- \\
-\end{array}$ & $\begin{array}{l}0,92^{*} \\
0,87^{* *} \\
0,91^{*} \\
0,99 * * \\
- \\
-\end{array}$ & $\begin{array}{c}\text { Angico } \\
-0,85 \\
-0,50^{*} \\
-0,58^{*} \\
-0,48^{*} \\
-0,60^{*} \\
-\end{array}$ & $\begin{array}{l}0,06 \mathrm{~ns} \\
0,60 * \\
0,49 \mathrm{~ns} \\
0,34 \mathrm{~ns} \\
0,21 \mathrm{~ns} \\
0,30 \mathrm{~ns}\end{array}$ & $\begin{array}{c}0,81^{*} \\
0,86^{*} \\
0,85^{*} \\
0,60^{*} \\
0,63^{*} \\
-0,73^{*}\end{array}$ & $\begin{array}{c}0,78^{*} \\
0,71^{*} \\
0,72^{*} \\
0,46 \mathrm{~ns} \\
0,53^{*} \\
-0,84^{*}\end{array}$ \\
\hline $\begin{array}{l}\mathrm{PST} \\
\mathrm{CE}_{\text {es }} \\
\mathrm{Na}-\mathrm{Solo} \\
\mathrm{Na} / \mathrm{K} \\
\mathrm{Na}-\mathrm{Pa} \\
\mathrm{MST}\end{array}$ & $\begin{array}{c}0,90^{* *} \\
0,55^{*} \\
-0,65^{*} \\
- \\
- \\
- \\
\end{array}$ & $\begin{array}{l}0,87^{*} \\
0,51^{*} \\
0,62^{*} \\
0,99 * * \\
- \\
- \\
\end{array}$ & $\begin{array}{l}\text { Aroeira } \\
-0,85^{*} \\
-0,65^{*} \\
-0,70^{*} \\
-0,68^{*} \\
-0,60^{*}\end{array}$ & $\begin{array}{l}-0,14 \mathrm{~ns} \\
0,26 \mathrm{~ns} \\
0,14 \mathrm{~ns} \\
-0,54^{*} \\
-0,61^{*} \\
-0,19 \mathrm{~ns}\end{array}$ & $\begin{array}{c}-0,89^{*} \\
-0,99^{*} * \\
-0,99^{*} * \\
-0,64^{*} \\
-0,61^{*} \\
0,70^{*}\end{array}$ & $\begin{array}{l}-0,53^{*} \\
-0,78^{*} \\
-0,71^{*} \\
-0,13 \text { ns } \\
-0,0 \text { ns } \\
0,71\end{array}$ \\
\hline $\begin{array}{l}\mathrm{PST} \\
\mathrm{CE}_{\text {es }} \\
\mathrm{Na}-\mathrm{Solo} \\
\mathrm{Na} / \mathrm{K} \\
\mathrm{Na}-\mathrm{Pa} \\
\mathrm{MST}\end{array}$ & $\begin{array}{c}0,84^{*} \\
0,85^{*} \\
0,85^{*} \\
- \\
- \\
- \\
\end{array}$ & $\begin{array}{c}0,82^{*} \\
0,91^{*} \\
0,90^{*} \\
0,98^{* *} \\
- \\
- \\
\end{array}$ & $\begin{array}{c}\text { Catingueir } \\
-0,97^{* *} \\
-0,73^{*} \\
-0,80^{*} \\
-0,86^{*} \\
-0,81^{*} \\
- \\
\end{array}$ & $\begin{array}{l} \\
-0,84 * \\
-0,99 * * \\
-0,98^{*} * \\
-0,87^{*} \\
-0,93^{*} \\
0,74^{*} \\
\end{array}$ & $\begin{array}{l}-0,83^{*} \\
-0,98^{* *} \\
-0,93^{*} \\
-0,60^{*} \\
-0,67^{*} \\
0,87^{*}\end{array}$ & $\begin{array}{r}-0,12 \mathrm{~ns} \\
0,26 \mathrm{~ns} \\
0,15 \mathrm{~ns} \\
0,42 \mathrm{~ns} \\
0,46 \mathrm{~ns} \\
-0,29 \mathrm{~ns} \\
\end{array}$ \\
\hline $\begin{array}{l}\mathrm{PST} \\
\mathrm{CE}_{\text {es }} \\
\mathrm{Na}-\mathrm{Solo} \\
\mathrm{Na} / \mathrm{K} \\
\mathrm{Na}-\mathrm{Pa} \\
\mathrm{MST}\end{array}$ & $\begin{array}{c}-0,05 \mathrm{~ns} \\
-0,59 \mathrm{~ns} \\
-0,49 \mathrm{~ns} \\
- \\
- \\
-\end{array}$ & $\begin{array}{c}-0,14 \mathrm{~ns} \\
-0,56 \mathrm{~ns} \\
-0,51 \mathrm{~ns} \\
0,87 \\
- \\
-\end{array}$ & $\begin{array}{c}\text { Pau-ferro } \\
-0,97^{* *} \\
-0,85^{*} \\
-0,89^{*} \\
0,10 \mathrm{~ns} \\
0,07 \mathrm{~ns} \\
-\end{array}$ & $\begin{array}{c}-0,78^{*} \\
-0,31 \mathrm{~ns} \\
-0,42 \mathrm{~ns} \\
-0,58^{*} \\
-0,46^{*} \\
0,73^{*}\end{array}$ & $\begin{array}{c}-0,39 * \\
0,17 \mathrm{~ns} \\
0,05 \mathrm{~ns} \\
-0,89 * \\
-0,72 * \\
0,32 \mathrm{~ns}\end{array}$ & $\begin{array}{c}0,0 \mathrm{~ns} \\
0,55 \mathrm{~ns} \\
0,44 \mathrm{~ns} \\
-0,99 * * \\
-0,84^{* *} \\
0,07 \mathrm{~ns}\end{array}$ \\
\hline
\end{tabular}

seca das espécies vegetais nos tratamentos envolvendo solo salino-sódico em relação ao solo não salino se deveu, provavelmente, ao estresse osmótico e ao acúmulo excessivo de sódio na parte aérea das plantas. A produção de matéria seca total (MST) de todas as espécies vegetais correlacionouse negativamente com o excesso de sais (CEes) e de sódio no solo (Na-solo), com o teor de sódio na parte aérea (Na-Pa) e com a relação sódio/potássio nesses tecidos. Resultados semelhantes foram obtidos em outros trabalhos (Miranda et al., 2002; Ferreira et al., 2007; Turan et al., 2009). Além do efeito tóxico direto do sódio interferindo no metabolismo vegetal (Taiz \& Zeiger, 2004), seu efeito negativo também se expressa pela inibição competitiva com íons como o cálcio, magnésio e potássio, diminuindo sua absorção, principalmente deste último (Mengel \& Kirkby, 2001; Taiz \& Zeiger, 2004).

As variáveis que expressam a salinidade (CE) e na sodicidade (PST e Na-solo) assim como os teores de sódio e a relação sódio/potássio, à exceção da espécie angico, se correlacionaram, em geral, negativamente, com as variáveis fisiológicas, sobretudo com a concentração intercelular de $\mathrm{CO}_{2}$ e com a condutância estomática (Tabela 6). Tais resultados estão de acordo com os obtidos em vários trabalhos (Parida et 
al., 2004; Marinho et al., 2005; Lima et al., 2007; Warren, 2008; Turan et al., 2009; Graciano et al., 2011). Isso ocorre porque o estresse salino provoca diminuição do potencial de turgescência dos tecidos foliares (Taiz \& Zeiger, 2004), provocando o fechamento dos estômatos, aumento da resistência à difusão do $\mathrm{CO}_{2} \mathrm{e}$ diminuição da taxa fotossintética (Romero-Aranda et al., 1998; Chaves et al., 2009).

\section{CONCLUSÕES}

1. A aplicação de sulfato de cálcio, enxofre elementar ou ácido sulfúrico, diminuiu a salinidade e a sodicidade do solo salino-sódico, tendo os dois últimos proporcionado as melhores condições químicas de solo para o crescimento das espécies avaliadas.

2. A aplicação de corretivos de reação ácida ou neutra favoreceu o crescimento e a produção de matéria seca das plantas, sendo a espécie pau-ferro a que se mostrou mais tolerante ao excesso de sais e sódio.

3. O excesso de sais e sódio no solo elevou os teores de sódio e a relação sódio/potássio na parte aérea, mas diminuiu a condutância estomática e a concentração intercelular de $\mathrm{CO}_{2}$.

\section{Agradecimento}

Ao CNPq, pelo auxílio financeiro, e ao CCTA/UFCG, pela infraestrutura necessária à execução da pesquisa.

\section{LITERATURA CITADA}

Amezketa, E.; Aragüés, R.; Gazol, R. Efficiency of sulfuric acid, mined gypsum, and two gypsum by-products in soil crusting prevention and sodic soil reclamation. Agronomy Journal, v.97, p.983-989, 2005.

Chaves, M. M.; Flexas, J.; Pinheiro, C. Photosynthesis under drought and salt stress: regulation mechanisms from whole plant to cell. Annals of Botany, v.103, p.551-560, 2009.

EMBRAPA- Empresa Brasileira Pesquisa Agropecuária. Manual de métodos de análise de solo. 2.ed. Rio de Janeiro: Embrapa Solos. 1997. 212p.

EMBRAPA- Empresa Brasileira Pesquisa agropecuária. Sistema brasileiro de classificação de solos. 2.ed. Rio de Janeiro: Embrapa Solos, 2006. 306p.

Fageria, N. K. Salt tolerance of rice cultivars. Plant and Soil, v.88, p.237-243, 1985.

Ferreira, P. A.; Garcia, G. O.; Neves, J. C. L.; Miranda, G. V.; Santos, D. B. Produção relativa do milho e teores foliares de nitrogênio, fósforo, enxofre e cloro em função da salinidade do solo. Revista Ciência Agronômica, v.38, p.7-16, 2007.

Freitas, R. M. O.; Nogueira, N. W.; Oliveira, F. N.; Costa, E. M.; Ribeiro, M. C. C. Efeito da irrigação com água salina na emergência e crescimento inicial de plântulas de jucá. Revista Caatinga, v.23, p.54-58, 2010.
Gharaibeh, M. A.; Eltaif, N. I.; Shunnar, O. F. Leaching and reclamation of calcareous saline-sodic soil by moderately saline and moderate-SAR water using gypsum and calcium chloride. Journal Plant Nutrition and Soil Science, v.172, p.713-719, 2009.

Gill, J. S.; Sale, P. W. G; Tang, C. Amelioration of dense sodic subsoil using organic amendments increases wheat yield more than using gypsum in a high rainfall zone of southern Australia. Field Crops Research, v.107, p.265-275, 2008.

Graciano, E. S. A.; Nogueira, R. J. M. C.; Lima, D. R. M.; Pacheco, C. M.; Santos, R. C. Crescimento e capacidade fotossintética da cultivar de amendoim BR 1 sob condições de salinidade. Revista Brasileira de Engenharia Agrícola e Ambiental, v.15, p.794-800, 2011.

Gupta, R. K.; Abrol, I. P. Salt-affected soils: their reclamation and manegement for crop production. Advances in Soil Science, v.11, p.224-88, 1990.

Hasegawa, P. M.; Bressan, R. A.; Zhu, J. K.; Bohnert, H. J. Plant cellular and molecular responses to high salinity. Annual Review of Plant Physiology and Plant Molecular Biology, v.51, p.463-499, 2000.

Holanda, A. C.; Santos, R. V.; Souto, J. S.; Alves, A. R. Desenvolvimento inicial de espécies arbóreas em ambientes degradados por sais. Revista de Biologia e Ciência da Terra, v.7, p.39-50. 2007.

Leal, I. G.; Accioly, A. M. A.; Nascimento, C. W. A.; Freire, M. B. G. S.; Montenegro, A. A. A. Ferreira, F. L. Fitorremediação de solo salino sódico por Atriplex nummularia e gesso de jazida. Revista Brasileira de Ciência do Solo, v.32, p.10651072,2008

Leite, E. M.; Cavalcante, L. F. C.; Diniz, A. A.; Santos, R, V.; Alves, G. S.; Lucena, Cavalcante, I. H. L. Correção da sodicidade de dois solos irrigados em resposta à aplicação de gesso agrícola. Irriga, v.12, p.168-176, 2007.

Lima, A. P. B.; Lobato, A. K. S.; Oliveira Neto, C. F.; Almeida, C. M.; Gouvêa, D. D. S.; Marques, L. C.; Cunha, R. L. M. Costa, R. C. L. Transpiração e condutância estomática em folhas de mudas de mogno (Swietenia macrophylla King R.A) submetidas ao estresse hídrico e à reidratação. Revista Brasileira de Biociências, v.5, p.933-935, 2007.

Malavolta, E. Elementos de nutrição mineral de plantas. Piracicaba: Ceres, 1980. 215p.

Malavolta, E.; Vitti, G.C.; Oliveira, S.A. Avaliação do estado nutricional das plantas: princípios e aplicações. Piracicaba: Associação Brasileira da Potassa e do Fosfato, 2. ed. 1997. 319p.

Marinho, F. J. L.; Gheyi, H. R.; Fernandes, P. D.; Ferreira Neto, M. Alterações fisiológicas em coqueiro irrigado com água salina. Revista Brasileira de Engenharia Agrícola e Ambiental, v.9, p.370-374, 2005.

Melo, R. M.; Barros, M. F. C; Santos, P. M.; Rolim, M. M. Correção de solos salino-sódicos pela aplicação de gesso mineral. Revista Brasileira de Engenharia Agrícola e Ambiental, v.12, p.376-380, 2008.

Mengel, K.; Kirkby, E. Principles of plant nutrition. 5.ed. Dordrecht/Boston/London: Kluwer Academic Publishers, 2001. 849p. 
Miranda, J. R. P.; Carvalho, J. G.; Santos, D. R.; Freire, A. L. O.; Bertoni, J. C.; Melo, J. R. M. \& Caldas, A. L. Silício e cloreto de sódio na nutrição mineral e produção de matéria seca de plantas de moringa (Moringa oleifera Lam.). Revista Brasileira de Ciência do Solo, v.26, p.957-965, 2002.

Mohamed, A. I.; Ali, O. M; M. A.; Matloub, M. A. Effect of soil amendments on some physical and chemical properties of some soils of Egypt under saline irrigation water. African Crop Science Conference Proceedings, v.8, p.1571-1578, 2007.

Munns, R. Comparative physiology of salt and water stress. Plant, Cell and Environmental, v.25, p.239-250, 2002.

Parida, A. K.; Das, A. B.; Mittra, B. Effects of salt on growth, ion accumulation photosynthesis and leaf anatomy of the mangrove, Bruguiera parviflora. Trees - Structure and Function, v.18, p.167-174, 2004.

Pazhanivelan, S.; Amanullah, M. M.; Vaiyapuri, K.; Athyamoorthi, K.; Radhamani, S. Influence of planting techniques and amendments on the performance of tamarind (Tamarindus indicus) and changes in soil properties in rainfed alkali soil. Research Journal of Agriculture and Biological Sciences, v.4, p.285-288, 2008.

Pitman, M. G.; Laüchli, A. Global impact of salinity and agricultural ecosystems. In: Salinity: Environment-PlantsMolecules. Laüchli, A.; Lüttge, U. (ed.), Dordrecht: Kluwer Academic, 2002. p.3-20.

Qadir, M.; Oster, J. D.; Schubert, S.; Noble, A. D.; Sahrawat, K. L. Phytoremediation of sodic and saline-sodic soils. Advances in Agronomy, v.96, p.197-247, 2007.

Qadir, M.; Steffens, D.; Yan, F.; Schubert, S. Sodium removal from a calcareous saline-sodic soil through leaching and plant uptake during phytoremediation. Land Degradation and Development, v.14, p.301-307, 2003.

Ribeiro, M. R.; Freire, F. J.; Montenegro, A. A. A. Solos halomórficos do Brasil: Ocorrência, gênese, classificação, uso e manejo sustentável. In: Curi, N.; Marques, J. J.; Guilherme, L. R. G.; Lima, J. M.; Lopes, A. S.; Alvarez, V. H. Tópicos em ciência do solo. Viçosa: Sociedade Brasileira de Ciência do Solo, v.3, 2003. 430p.
Richards, L. A. Diagnosis and improvement of saline and alkali soils. Washington: US Department of Agriculture, 1954. 160p. USDA Agricultural Handbook, 60.

Romero-Aranda, R.; Moya, J. L.; Tadeo, F. R.; Lagaz, F.; PrimoMillo, E.; Talon, M. Physiological and anatomical disturbances induced by chloride salts in sensitive and tolerant citrus: beneficial and detrimental effects of cations. Plant, Cell and Environmental, v.21, p.1243-1253, 1998.

Stamford, N. P.; Freitas, A. D. S.; Ferraz, D. S.; Santos, C. E. S. Effect of sulphur inoculated with Thiobacillus on saline soils amendment and growth of cowpea and yam bean legumes. Journal of Agriculture Science, v.139, p.275-281, 2002.

Stamford, N. P.; Ribeiro, M. R.; Cunha, K. P. V. Effectiveness of sulfur with Acidithiobacillus and gypsum in chemical attributes of a Brazilian sodic soil. World Journal Microbiology Biotechnology, v.23, p.1433-1439, 2007.

Taiz, L.; Zeiger, E. Fisiologia do estresse. In: Taiz, L.; Zeiger, E. Fisiologia vegetal. Artmed: Califórnia, 2004. 719p.

Tertuliano, S. S. X.; Santos, R. V. Crescimento de espécies arbóreas em solo salino-sódico tratado com ácido sulfúrico. Revista Brasileira de Engenharia Agrícola e Ambiental, v.2, p.239-242, 1998.

Turan, M. A.; Elkarim, A. H. A.; Taban, N. T. S. Effect of salt stress on growth, stomatal resistance, proline and chlorophyll concentrations on maize plant. African Journal of Agricultural Research, v.4, p.893-897, 2009.

Vital, A. F. M.; Santos, R. V.; Cavalcante, L. F. C.; Souto, J. S. Comportamento de atributos químicos de um solo salinosódico tratado com gesso e fósforo Revista Brasileira de Engenharia Agrícola e Ambiental, v.9, p.30-36, 2005.

Warren, C. R. Soil water deficits decrease the internal conductance to $\mathrm{CO}_{2}$ transfer but atmospheric water déficits do not. Journal of Experimental Botany, v.59, p.327:334, 2008.

Zia, M. H.; Sabir, S. M.; Ghafoor, A.; Murtaza, G. Effectiveness of sulphuric acid and gypsum for the reclamation of a calcareous saline-sodic soil under four crop rotations. Journal Agronomy \& Crop Science, v.193, p.262-269, 2007. 